\title{
Development of Membrane Filter with Oligosaccharide Immobilized by Click Chemistry for Influenza Virus Adsorption
}

\author{
Tomohisa Kato ${ }^{1,2}$, Atsushi Miyagawa ${ }^{1,3}$, Maria Carmelita Z. Kasuya ${ }^{3}$ and Kenichi Hatanaka ${ }^{*}, 3$ \\ ${ }^{1}$ Japan Chemical Innovation Institute, 1-3-5 Jimbocho, Chiyoda-ku, Tokyo 101-0051, Japan \\ ${ }^{2}$ Kaneka Corporation, 3-2-4, Nakanoshima, Kita-ku, Osaka 530-8288, Japan \\ ${ }^{3}$ Institute of Industrial Science, The University of Tokyo, 4-6-1, Komaba, Meguro-ku, Tokyo 153-8505, Japan
}

\begin{abstract}
Membranes with immobilized GM3-type oligosaccharide were prepared and influenza virus adsorption was evaluated. GM3-type oligosaccharide which has azido group in the aglycon was synthesized by saccharide primer method. The azido group was used for combination by click chemistry with alkyne which is introduced to membranes. The position of the azido group in the aglycon of GM3-type oligosaccharide was either the farthest (12-azidododecyl), or the nearest (2-azidododecyl). The azido group in the farthest position showed higher reactivity with alkyne on the membrane than the one in the nearest the GM3-type oligosaccharide. Moreover, the membrane immobilized GM3-type oligosaccharide showed adsorption ability of influenza virus.
\end{abstract}

Keywords: GM3, click chemistry, immobilization, influenza virus.

\section{INTRODUCTION}

Recently, the study of oligosaccharides have remarkably advanced, and it became clear that oligosaccharides had binding capacity with hormone, toxin, and virus particles and play important roles for various life phenomena such as cell recognition, cell differentiation, cell growth, carcinogenesis, and the cell adhesion [1, 2]. Moreover, oligosaccharides have been reported to be used for applications in disease diagnosis, detection and removal of viruses and toxins, and targeted drug delivery system [3-6].

Influenza is one of the most common existing infections to both human and animal in the world. Influenza virus has three types (A, B and C), where types $\mathrm{A}$ and $\mathrm{B}$ cause the influenza of human. Type A influenza virus in particular has much mutation of hemagglutinin (HA) and neuraminidase (NA). Nine and sixteen kinds of major mutation have been found in HA and NA, respectively [7]. The subtype of influenza virus is decided by these variational pairs. During infection of the influenza virus, HA binds to the sialic acid (SA) which is linked to galactose (SA-Gal) on a host cell surface. Human influenza virus and avian influenza virus greatly vary in affinity with SA-Gal by the bond style of sialic acid. $\mathrm{Hu}-$ man influenza virus and avian influenza virus are specific to SA $\alpha 2,6 \mathrm{Gal}$ and SA $\alpha 2,3 \mathrm{Gal}$, respectively [8-10]. However, some reports reviewed that even avian influenza virus might acquire the ability to infect human. Hence, it is possible that the affinity for the bond style of the sialic acid of influenza virus may change [11].

\footnotetext{
*Address correspondence to this author at the Institute of Industrial Science, The University of Tokyo, 4-6-1, Komaba, Meguro-ku, Tokyo 153-8505, Japan; Tel: +81-3-5452-6355; Fax: +81-3-5452-6356;

E-mail: hatanaka@iis.u-tokyo.ac.jp
}

Recently, a novel synthetic method for obtaining oligosaccharide with the functional group was developed [12, 13]. In this method, while the cells were cultured in the medium supplemented with the saccharide primer (for example, 12 -azidododecyl $\beta$-lactoside) with the functional group, the saccharide primer was taken into the cells and glycosylated by cellular glycosyltransferases in golgi. The glycosylated primers were secreted in the culture medium. Besides this, an efficient purification method for the glycosylated primers by using centrifugal partition chromatography (CPC) has been reported $[14,15]$.

Click chemistry for azide and alkyne cycloaddition was developed in 2001 [16]. Click chemistry is a very superior reaction because it has extremely high selectivity and efficiency and proceeds even in water. This reaction can not be used for in situ reaction due to the cytotoxicity of copper ion. But in the fields of chemical and organic materials, many remarkable achievements have been reported [17]. Recently, a method for visualization of glycoconjugates in cells by using alkynyl or azido-containing sugar analog was reported $[18,19]$. The sugar analog incorporated into glycoproteins or glycolipids can be detected by labeling with probe based on click chemistry.

In this paper, we developed a simple method for the preparation of a membrane to which GM3-type oligosaccharide was immobilized by click chemistry. Moreover, the ability of the prepared membrane for influenza virus adsorption was evaluated.

\section{MATERIALS AND METHODS}

\subsection{Preparation of Azidododecyl $\beta$-Lactoside and Dodecyl $\beta$-Lactoside}

2-Azidododecyl and 12-azidododecyl $\beta$-lactosides, were prepared as described in literature [1]. For the preparation of 
azidododecyl $\beta$-lactosides, a dichloroethane soln. of 2-azido1-dodecanol (or 12-azido-1-dodecanol) (1.34 g, $5.89 \mathrm{mmol}$ ), lactose octaacetate $(2.0 \mathrm{~g}, 2.87 \mathrm{mmol})$ and $4-\AA$ molecular sieves were stirred at $50{ }^{\circ} \mathrm{C}$ for $1.5 \mathrm{~h}$. Then, $\mathrm{BF}_{3} \cdot \mathrm{OEt}_{2}(0.5$ $\mathrm{ml}$ ) was added, and the soln. was stirred at $50^{\circ} \mathrm{C}$. After $3 \mathrm{~h}$, the mixture was diluted with chloroform, and the chloroform soln. was neutralized with aq. $\mathrm{NaHCO}_{3}$, washed with $\mathrm{H}_{2} \mathrm{O}$, dried with anhydrous $\mathrm{Na}_{2} \mathrm{SO}_{4}$ and concentrated. Purification was performed by column chromatography (silica gel 60, 70230 mesh, Merck, Darmstadt, Germany; hexane/AcOEt 2:1, $\mathrm{v} / \mathrm{v})$. Dodecyl lactoside was prepared by the method described in the literature [20].

\subsection{Preparation of GM3-Type Oligosaccharide}

GM3-type oligosaccharides were synthesized using the saccharide primer method as described previously [14]. Substituted $n$-dodecyl $\beta$-lactoside was glycosylated in mouse melanoma B16 cells, and the GM3-type oligosaccharide was collected from the culture medium. The GM3-type oligosaccharide was concentrated by using a polystyrene adsorption resin, Diaion HP20 (Mitsubishi Chemical, Tokyo, Japan), and purified using centrifugal partition chromatography.

\subsection{Introduction of the Alkyne to a Membrane}

Initially, a carboxyl group was introduced into the cellulose membrane as described previously [5, 21]. 20 pieces of cellulose membranes (No.41, $\phi=55 \mathrm{~mm}$, Whatman, Maidstone, U.K.) were incubated in a mixture of $1 \mathrm{M} \mathrm{NaOH}$ and saturated $\mathrm{NaCl}$ solution (1:1) with stirring for $1 \mathrm{~h}$, followed by the addition of $2 \mathrm{~g}$ of bromoacetic acid to the solution. After incubation for $16 \mathrm{~h}$, the membranes were washed with water until the washings became neutral. Then, 20 pieces of membranes with carboxyl group were soaked into $15 \mathrm{~mL}$ of $\mathrm{H}_{2} \mathrm{O}$, followed by the addition of $80 \mathrm{mg}$ of 2-propynylamine and $200 \mathrm{mg}$ of 4-(4,6-dimethoxy-1,3,5-triazin-2-yl)-4-methylmorpholinium chloride (DMT-MM). After shaking gently for $16 \mathrm{~h}$, the membranes were washed five times with 100 $\mathrm{mL}$ of $\mathrm{H}_{2} \mathrm{O}$ and dried as shown in Scheme $\mathbf{1}$.

\subsection{Fluorescent Labeling of Lactose Derivatives}

$8.3 \mathrm{mg}$ of 4-( $N, N$-dimethylaminosulfonyl)-7-( $N$-chloroformylmethyl-N-methylamino)-2,1,3-benzoxadiazole (DBD-COCl) (Tokyo Chemical Industry, Tokyo, Japan) was dissolved in 1 $\mathrm{ml}$ of $N, N$-dimethylformamide (DMF). $500 \mathrm{nmol}$ of lactose derivative (dodecyl $\beta$-lactoside, 2-azidododecyl, or 12-azidododecyl $\beta$-lactoside) were dissolved in $1 \mathrm{ml}$ of DMF containing $0.5 \mathrm{M}$ of quinuclidine. The $\mathrm{DBD}-\mathrm{COCl}$ solution and lactose derivative solution were mixed and reacted at $60^{\circ} \mathrm{C}$ for 3 h. The dried products were dissolved in $100 \mu$ l of dimethyl sulfoxide (DMSO), diluted with $10 \mathrm{ml}$ of water and then purified by using Sep-Pak C18 (Waters, Milford, MA, USA). After dialysis (MWCO500) for 2 days, the sample solutions were freeze-dried.

\subsection{Immobilization of the Carbohydrate Chain to the Membrane by Click Chemistry}

Click chemistry reaction was performed as described previously [22]. A solution of the fluorescent labeled lactose derivative $(500 \mathrm{nmol})$, one piece of $1 \mathrm{~cm}^{2}$ membrane with alkyne, N,N-diisopropylethylamine $(0.05 \mathrm{mg}, 0.38 \mu \mathrm{mol})$, and $\mathrm{Cu}\left(\mathrm{PPh}_{3}\right)_{3} \mathrm{Br}(11 \mu \mathrm{g}, 0.025 \mu \mathrm{mol})$ in tetrahydrofuran (1 $\mathrm{mL})$ was prepared. The reaction mixtures were then placed in a sealed vial and were stirred at room temperature for ca. $48 \mathrm{~h}$. $\mathrm{Cu}\left(\mathrm{PPh}_{3}\right)_{3} \mathrm{Br}$ was synthesized as described in literature [23]. The reaction products were washed ten times with tetrahydrofuran. Both 12-azidododecyl sialyllactoside (GM3type oligosaccharide) and 12-azidododecyl $\beta$-lactoside were immobilized to membranes by the same method as above.

\subsection{Assay for Influenza Virus Adsorption}

Assays for influenza virus adsorption were performed as described in literature $[21,24]$. Ca. $0.25 \mathrm{~cm}^{2}$ of oligosaccharide immobilized membranes were incubated in $200 \mu \mathrm{l}$ of 5 $\times$ Denhardt's solution containing $10 \mathrm{mg} / \mathrm{mL}$ salmon sperm DNA at room temperature for $30 \mathrm{~min}$. Then the membranes were transferred into various kinds of concentration of influenza virus (A/PR/8/34) (obtained from University of Tsukuba) solutions $(100 \mu \mathrm{L})$. The influenza virus solutions were prepared as follows. 3 , 9, or $30 \mu \mathrm{L}$ of ca. $10^{9} \mathrm{pfu} / \mathrm{mL}$ influenza virus were mixed with $1 \mathrm{~mL}$ of PBS $(-)(\times 3, \times 9$, $\times 30$ ). After incubation at room temperature for $10 \mathrm{~min}$, the viral solutions were removed and washed three times with $200 \mu \mathrm{L}$ of PBS (-). Then, $15 \mu$ Lof $1 \times$ SDS-PAGE sample buffer was added and incubated at $100^{\circ} \mathrm{C}$ for $5 \mathrm{~min}$. The viral eluates were then separated by SDS-PAGE and transferred to a PVDF membrane (Millipore, Bedford, MA). Western blotting was performed using an anti-A/PR/8/34 antibody (obtained from University of Tsukuba) and a secondary antibody, rabbit anti-species-specific immunoglobulin conjugate to horseradish peroxidase (given from University of Tsukuba), followed by detection with the ECL Western blotting Detection System (GE Healthcare, Piscataway, NJ, USA).

\section{RESULTS AND DISCUSSION}

\subsection{Introduction of Alkyne to the Membrane}

The hydroxyl groups of cellulose membranes were carboxymethylated with bromoacetic acid. The quantity of carboxyl groups introduced into membranes was analyzed by a neutralization titration method and was found to be 16.0 $\mu$ mol carboxyl groups per piece of membrane. Then, alkyne groups were introduced into the membranes by condensation of the carboxymethyl groups and 2-propynylamine using DMT-MM. The quantity of introduced alkyne group was analyzed by a neutralization titration method and was calculated from the decrement of carboxylmethyl groups. 12.3 $\mu \mathrm{mol}$ alkyne groups were introduced to each piece of membrane.

\subsection{Immobilization of Oligosaccharides by Click Chemistry}

The cellulose membranes, to which alkyne groups were introduced, were used as carrier to immobilize oligosaccharides. For the immobilization of oligosaccharide, the azido group was introduced in the aglycon of saccharide primer (dodecyl lactoside). The azido group is introduced in two positions of the aglycon. For detection, the sccharide primers were labeled by using DBD $\mathrm{COCl}$. DBD-COCl reacts with a hydroxyl group and forms a stable fluorescence adduct [25]. The hydroxyl groups of lactose were labeled by $\mathrm{DBD}-\mathrm{COCl}$ and showed intense fluorescence at long excitation and emission 


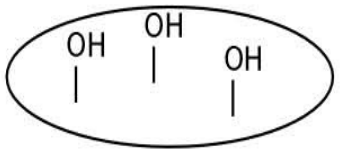

Cellulose membrane

1

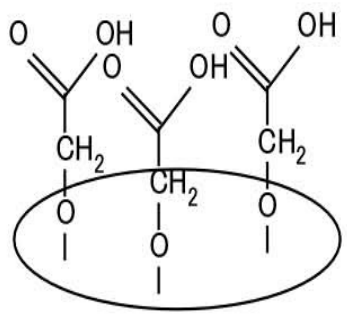

2

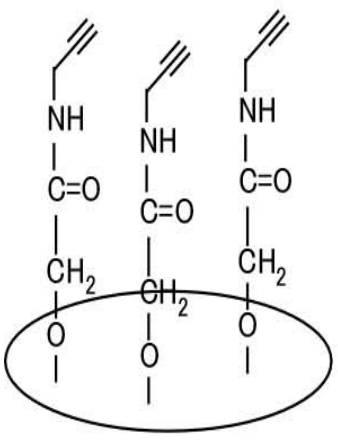

3

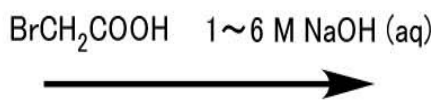

saturated $\mathrm{NaCl}(\mathrm{aq})$

Carboxymethylated cellulose membrane

2

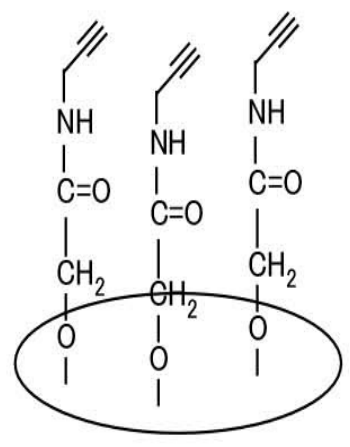

3

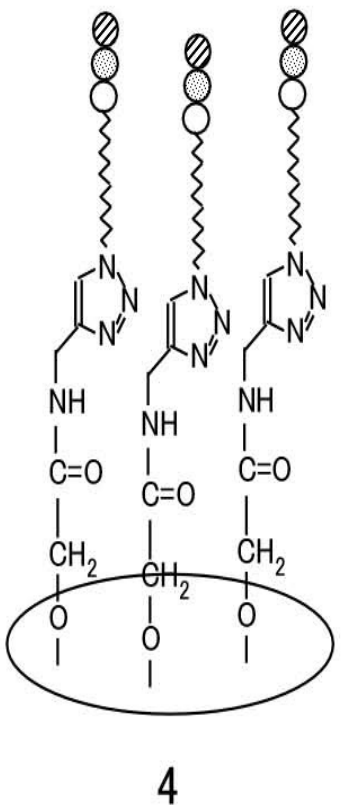

Scheme 1. Preparation of cellulose membrane with immobilized saccharide units by click chemistry reaction.

wavelengths (450 and $560 \mathrm{~nm}$, respectively), a distinct advantage for detection. The remaining unreacted $\mathrm{DBD}-\mathrm{COCl}$ was hydrolyzed by $\mathrm{H}_{2} \mathrm{O}$ during Sep-Pak procedure. Three kinds of DBD-labeled saccharide primers (2-azidododecyl lactoside, 12-azidododecyl lactoside, and dodecyl lactoside) were reacted by click chemistry with the alkyne introduced to cellu- lose membranes. The reacted membranes were washed to remove unreacted oligosaccharides and dried.

The oligosaccharides immobilized to the cellulose membrane were detected with UV light (365 and $450 \mathrm{~nm}$ ). As shown in Fig. (1), stronger fluorescence color development was found in 12-azidododecyl lactoside which has the azide group at the end of the aglycon. On the other hand, the fluo- 


\section{(a)}

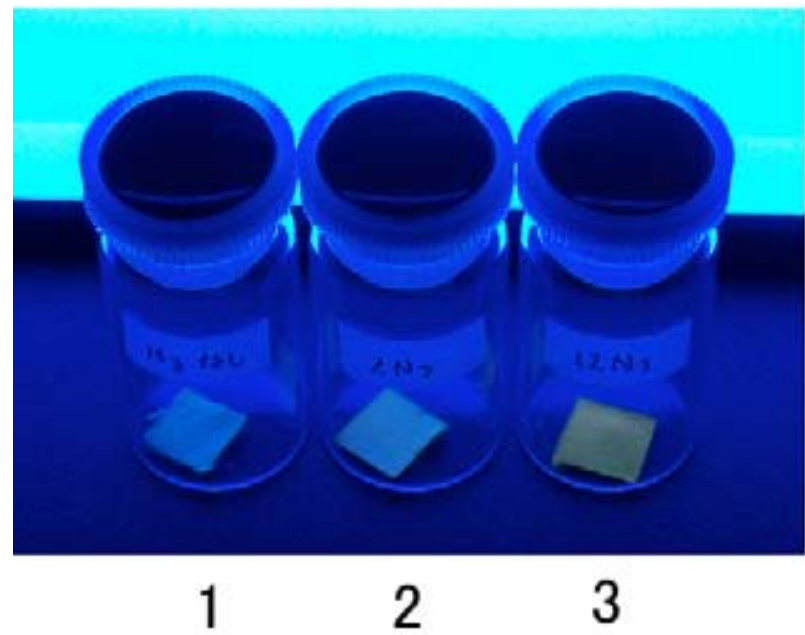

(b)

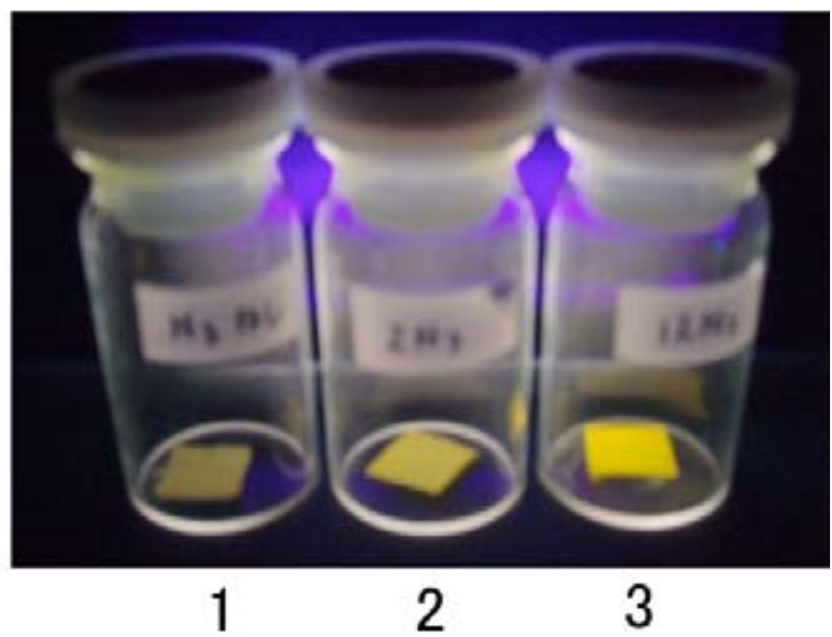

Fig. (1). Comparison between immobilization efficiency of 2-azidododecyl lactoside and 12-azidododecyl lactoside by click chemistry. 1: dodecyl lactoside (Control); 2: 2-azidododecyl lactoside; 3: 12-azidododecyl lactoside. The oligosaccharides immobilized to the cellulose membrane were detected with UV light of (a) $450 \mathrm{~nm}$ and (b) $365 \mathrm{~nm}$.

rescence color development was not found in dodecyl lactoside which does not have an azide group and fluorescence color development was very weak for 2-azidododecyl lactoside which has the azide group at the root of the aglycon. From these results, it was found that it is desirable for immobilization of azidododecyl lactoside to add the functional group at the end than at the root of the aglycon. Probably, the azido group nearest to lactose is difficult to react with the alkyne group of cellulose membrane due to steric hindrance.

\subsection{The Influenza Virus Adsorption Ability of GM3-Type Oligosaccharide Immobilized Membranes}

The GM3-type oligosaccharide was obtained by saccharide primer method using mouse melanoma B16 cells and 12-azidododecyl lactoside. GM3-type oligosaccharide which has azido group at the root of the aglycon was immobilized to cellulose membrane by click chemistry. It has been reported that the sialic acid residue of sialyl lactose produced by B16 cells is $\alpha-(2 \rightarrow 3)$ linked [1]. Evaluation of the adsorption ability of the influenza virus was performed to the membrane to which sialyl lactose was immobilized.

The virus adsorption capacity of the membrane with or without immobilized sialyl lactose was compared employing various concentration ranges of viral solution (Fig. 2). The virus adsorption to the membrane with immobilized lactose and GM3-type oligosaccharide ( $\alpha$-2,3-sialyl lactose) are shown in Fig. (2) lanes 3-5 and lanes 6-8, respectively. By comparing lanes 5 and 8 , it was found that influenza virus easily adsorbed onto sialyl lactose.

\section{CONCLUSIONS}

This simple and easy method for the preparation of the oligosaccharide immobilized materials is expected to play an important role to utilize useful oligosaccharides. In this paper, the membrane with immobilized sialyl lactose showed potential for removal of influenza virus. If the functions of the oligosaccharides or the interaction between oligosaccharides and various kinds of biological molecules are further determined, we can widen the potential for application to high-performance materials in the future.

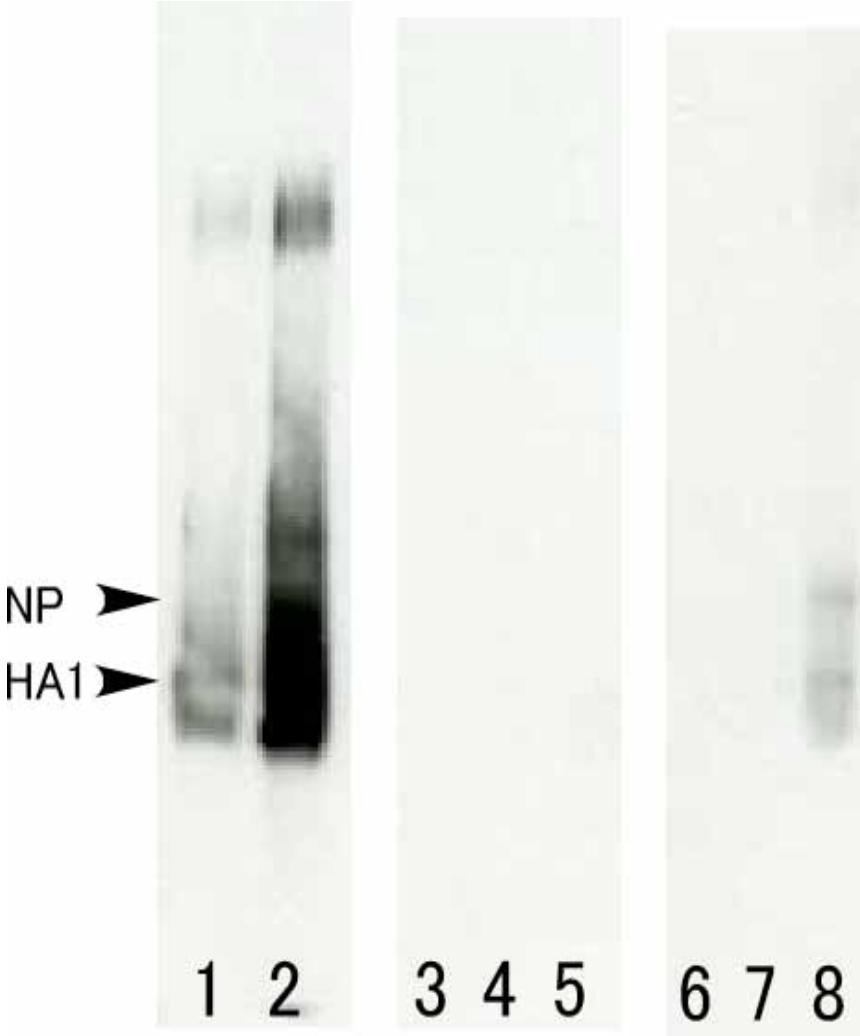

Fig. (2). Virus adsorption tests of the oligosaccharide immobilized membranes. Lane 1,2: Standard (A/PR/8/34); 3-5: 12-azidododecyl lactoside; 6-8: 12 -azidododecyl $\alpha 2,3$-sialyl lactoside. The quantity of influenza virus $(\mathrm{A} / \mathrm{PR} / 8 / 34)$ which we used for an experiment is as follows. Lane $3,6: \times 1 ; 4,7: \times 3 ; 5,8: \times 10$. 


\section{ACKNOWLEDGEMENTS}

This work was supported by a grant for "Development of Novel Diagnostic and Medical Applications through Elucidation of Sugar Chain Functions" from New Energy and Industrial Technology Development Organization (NEDO). The authors thank Prof. K. Nagata and Dr. A. Kawaguchi (University of Tsukuba, Tsukuba, Japan) for their helpful discussions and technical support on this study.

$$
\begin{aligned}
& \text { ABBREVIATIONS } \\
& \text { CPC = Centrifugal partition chromatography } \\
& \text { DBD-COCl }=4-(N, N \text {-Dimethylaminosulfonyl })-7- \\
& \text { ( } N \text {-chloroformylmethyl-N-methylamino)- } \\
& \text { 2,1,3-benzoxadiazole } \\
& \text { DMF } \quad=\text { Dimethylformamide } \\
& \text { DMSO = Dimethyl sulfoxide } \\
& \text { DMT-MM = 4-(4,6-Dimethoxy-1,3,5-triazin-2-yl)-4- } \\
& \text { methylmorpholinium chloride } \\
& \text { HA }=\text { Hemagglutinin } \\
& \text { NA } \quad=\text { Neuraminidase } \\
& \text { PBS = Phosphate buffered saline } \mathrm{pH} 7.6 \\
& \text { PVDF = Polyvinylidene difluoride } \\
& \text { SA } \quad=\text { Sialic acid } \\
& \text { SA-Gal }=\text { Sialic acid linked with galactose } \\
& \text { SDS-PAGE = Sodium dodecyl sulfate-polyacrylamide gel }
\end{aligned}
$$

\section{REFERENCES}

[1] Murozuka, Y.; Kasuya, M.C.Z.; Kobayashi, M.; Watanabe, Y.; Sato, T.; Hatanaka, K. Efficient sialylation on azidododecyl lactosides by using B16 melanoma cells. Chem. Biodivers., 2005, 2, 1063.

[2] Varki, A. Biological roles of oligosaccharides: all of the theories are correct. Glycobiology, 1993, 3, 97.

[3] Uemura, M.; Sakaguchi, T.; Uejima, T.; Nozawa, S.; Narimatsu, H. Mouse monoclonal antibodies which recognize a human (beta 14)galactosyl-transferase associated with tumor in body fluids. Cancer Res., 1992, 52, 6153.

[4] Zeisig, R.; Stahn, R.; Wenzel, K.; Behrens, D.; Fichtner, I. Effect of sialyl Lewis X-glycoliposomes on the inhibition of E-selectinmediated tumour cell adhesion in vitro. Biochim. Biophys. Acta, 2004, 1660, 31 .

[5] Miyagawa, A.; Watanabe, M.; Igai, K.; Kasuya, M.C.Z.; Natori, Y.; Nishikawa, K.; Hatanaka, K. Development of dialyzer with immobilized glycoconjugate polymers for removal of Shiga-toxin. Biomaterials, 2006, 27, 3304

[6] Zhu, J.; Xue, J.; Guo, Z.; Zhang, L.; Marchant, R.E. Biomimetic glycoliposomes as nanocarriers for targeting P-selectin on activated platelets. Bioconjug. Chem., 2007, 18, 1366.

[7] Fouchier, R.A.; Munster, V.; Wallensten, A.; Bestebroer, T.M.; Herfst, S.; Smith, D.; Rimmelzwaan, G.F.; Olsen, B.; Osterhaus,
A.D. Characterization of a novel influenza A virus hemagglutinin subtype (H16) obtained from black-headed gulls. J. Virol., 2005, 79, 2814.

[8] Rogers, G.N.; Pritchett, T.J.; Lane, J.L.; Paulson, J. C. Differential sensitivity of human, avian, and equine influenza $\mathrm{A}$ viruses to a glycoprotein inhibitor of infection: selection of receptor specific variants. Virology, 1983, 131, 394

[9] Matrosovich, M.; Tuzikov, A.; Bovin, N.; Gambaryan, A.; Klimov, A.; Castrucci, M. R.; Donatelli, I.; Kawaoka, Y. Early alterations of the receptor-binding properties of $\mathrm{H} 1, \mathrm{H} 2$, and $\mathrm{H} 3$ avian influenza virus hemagglutinins after their introduction into mammals. $J$. Virol., 2000, 74, 8502

[10] Suzuki Y. Host mediated variation and receptor binding specificity of influenza viruses. Adv. Exp. Med. Biol., 2001, 491, 445.

[11] Stevens, J.; Blixt, O.; Tumpey, T.M.; Taubenberger, J.K.; Paulson, J.C.; Wilson, I.A. Structure and receptor specificity of the hemagglutinin from an H5N1 influenza virus. Science, 2006, 312, 404.

[12] Kasuya, M.C.Z.; Wang, L.X.; Lee, Y.C.; Mitsuki, M.; Nakajima, H.; Miura, Y.; Sato, T.; Hatanaka, K.; Yamagata, S.; Yamagata, T. Azido glycoside primer: a versatile building block for the biocombinatorial synthesis of glycosphingolipid analogues. Carbohydr. Res., 2000, 329, 755.

[13] Sato, T.; Hatanaka, K.; Hashimoto, H.; Yamagata, T. Syntheses of oligosaccharides using cell function. Trends Glycosci. Glycotechnol., $\mathbf{2 0 0 7}, 105,1$.

[14] Kato, T.; Miyagawa, A.; Kasuya, M.C.Z.; Ito, A.; Hatanaka, K. Purification by centrifugal partition chromatography of amphiphilic compounds, glycolipids and pseudo-glycolipids synthesized by using cells. J. Chromatogr. A, 2008, 1178, 154.

[15] Kato, T.; Hatanaka, K. Purification of gangliosides by liquid-liquid partition chromatography. J. Lipid Res., 2008, 49, 2474.

[16] Kolb, H.C.; Finn, M.G.; Sharpless, K.B. Click chemistry: Diverse chemical function from a few good reactions. Angew. Chem. Int Ed. Engl., 2001, 40, 2004

[17] Moses, J.E.; Moorhouse, A.D. The growing applications of click chemistry. Chem. Soc. Rev., 2007, 36, 1249.

[18] Sawa, M.; Hsu, T.L.; Itoh, T.; Sugiyama, M.; Hanson, S.R.; Vogt, P.K.; Wong, C.H. Glycoproteomic probes for fluorescent imaging of fucosylated glycans in vivo. Proc. Natl. Acad. Sci. USA, 2006, $103,12371$.

[19] Hsu, T.L.; Hanson, S.R.; Kishikawa, K.; Wang, S.K.; Sawa, M. Wong, C.H. Alkynyl sugar analogs for the labeling and visualization of glycoconjugates in cells. Proc. Natl. Acad. Sci. USA, 2007, 104, 2614.

[20] Zimmermann, P.; Sommer, R.; Bär, T.; Schmidt, R.R. Azidosphingosine glycosylation in glycosphingolipid synthesis. J. Carbohydr. Chem., 1988, 7, 435.

[21] Miyagawa, A.; Nakane, M.; Hatanaka, K. Applications of immobilized glycopolymers. Seisankenkyu, 2007, 59, 110.

[22] Malkoch, M.; Schleicher, K.; Drockenmuller, E.; Hawker, C.J. Russell, T.P.; Wu, P.; Fokin, V.V. Structurally diverse dendritic libraries: A highly efficient functionalization approach using click chemistry. Macromolecules, 2005, 38, 3663.

[23] Gujadhur, R.; Venkataraman, D.; Kintigh, J.T. Formation of arylnitrogen bonds using a soluble copper(I) catalyst. Tetrahedron Lett., 2001, 42, 4791.

[24] Kawaguchi, A.; Naito, T.; Nagata, K. Involvement of influenza virus PA subunit in assembly of functional RNA polymerase complexes. J. Virol., 2005, 79, 732.

[25] Imai, K.; Fukushima, T.; Yokosu, H. A novel electrophilic reagent, 4 (N-chloroformylmethyl-N-methyl)amino-7-N,N-dimethylaminosulphonyl-2,1,3-benzoxadiazole (DBD-COCl) for fluorometric detection of alcohols, phenols, amines and thiols. Biomed. Chromatogr., 1994, 8, 107. 